\title{
Pulmonary Embolism: Contemporary Medical Management and Future Perspectives
}

\author{
Stefano Barco, MD, $\mathrm{PhD}^{1}$ and Stavros V. Konstantinides, MD, PhD ${ }^{1,2}$
}

Pulmonary embolism (PE) contributes substantially to the global disease burden. A key determinant of early adverse outcomes is the presence (and severity) of right ventricular dysfunction. Consequently, risk-adapted management strategies continue to evolve, tailoring acute treatment to the patients' clinical presentation, hemodynamic status, imaging and biochemical markers, and comorbidity. For subjects with hemodynamic instability or 'high-risk' PE, immediate systemic reperfusion treatment with intravenous thrombolysis is indicated; emerging approaches such as catheter-directed pharmacomechanical reperfusion might help to minimize the bleeding risk. Currently, direct, nonvitamin K-dependent oral anticoagulants are the mainstay of treatment for acute PE. They have been shown to simplify initial and extended anticoagulation regimens while reducing the bleeding risk compared to vitamin $\mathrm{K}$ antagonists. (This is a review article based on the invited lecture of the 37th Annual Meeting of Japanese Society of Phlebology.)

Keywords: pulmonary embolism, venous thromboembolism, direct oral anticoagulants, thrombolysis, right ventricular dysfunction, risk stratification

${ }^{1}$ Center for Thrombosis and Hemostasis, University Medical Center of the Johannes Gutenberg University, Mainz, Germany

${ }^{2}$ Department of Cardiology, Democritus University of Thrace, Alexandroupolis, Greece

Received: April 22, 2018; Accepted: May 22, 2018

Corresponding author: Stavros V. Konstantinides, MD, PhD. Center for Thrombosis and Hemostasis, University Medical Center of the Johannes Gutenberg University Mainz, Langenbeckstrasse 1, Building 403, 55131 Mainz, Germany

Tel: +49-6131-17-8382, Fax: +49-6131-17-3456

E-mail: stavros.konstantinides@unimedizin-mainz.de

This is a review article based on the invited lecture of the 37 th Annual Meeting of Japanese Society of Phlebology.

(cc) BY-NC-SA (C2018 The Editorial Committee of Annals of Vascular Diseases. This article is distributed under the terms of the Creative Commons Attribution License, which permits use, distribution, and reproduction in any medium, provided the credit of the original work, a link to the license, and indication of any change are properly given, and the original work is not used for commercial purposes. Remixed or transformed contributions must be distributed under the same license as the original.

\section{Introduction}

After acute myocardial infarction and stroke, acute pulmonary embolism (PE) is the third most frequently diagnosed acute cardiovascular manifestation syndrome, and represents a major cause of acute and long-term mortality and morbidity. Depending on the clinical severity, and particularly the presence of hemodynamic instability at presentation, up to $30 \%$ of patients with acute PE may die within the first 30 days, ${ }^{1}$ and as many as $30 \%$ of survivors will later develop potentially life-threatening recurrent venous thromboembolism (VTE) or some sort of chronic disabling symptoms. ${ }^{2)}$ Moreover, a variable proportion of $\mathrm{PE}$ patients ranging between $1 \%$ and $9 \%$ are at risk of presenting, over the long term, with a devastating complication termed chronic thromboembolic pulmonary hypertension (CTEPH). ${ }^{2,3)}$ The direct costs related to acute PE have been estimated to be at least twice as high as those for the management of deep vein thrombosis, and spending virtually "explodes" when it comes to the management of patients with CTEPH. ${ }^{4-6)}$ Finally, since the risk of VTE approximately doubles with each decade after the age of 40 and, thus, an increasing number of individuals in ageing societies will suffer from the disease and its sequelae in the years to come, it is certain that the impact of PE will continue to increase in the future.

\section{Risk-Adapted Management Strategies}

Current international guidelines emphasize that the appropriate management of patients with confirmed acute PE requires their stratification into classes of disease severity to create an algorithm which adjusts the modalities of medical, surgical, or interventional treatment to the early death or complication risk (Fig. 1). ${ }^{7)}$ Patients with clinically overt right ventricular failure on admission, which manifests as persistent arterial hypotension accompanied by signs of end-organ hypoperfusion, are classified into the high-risk (or "massive") PE category. These patients exhibit 30 -day fatality rates of $20 \%-40 \%$ or even higher, and in addition to medical or pharmacomechanical reperfusion, they are in need of immediate treatment of acute right heart failure. 


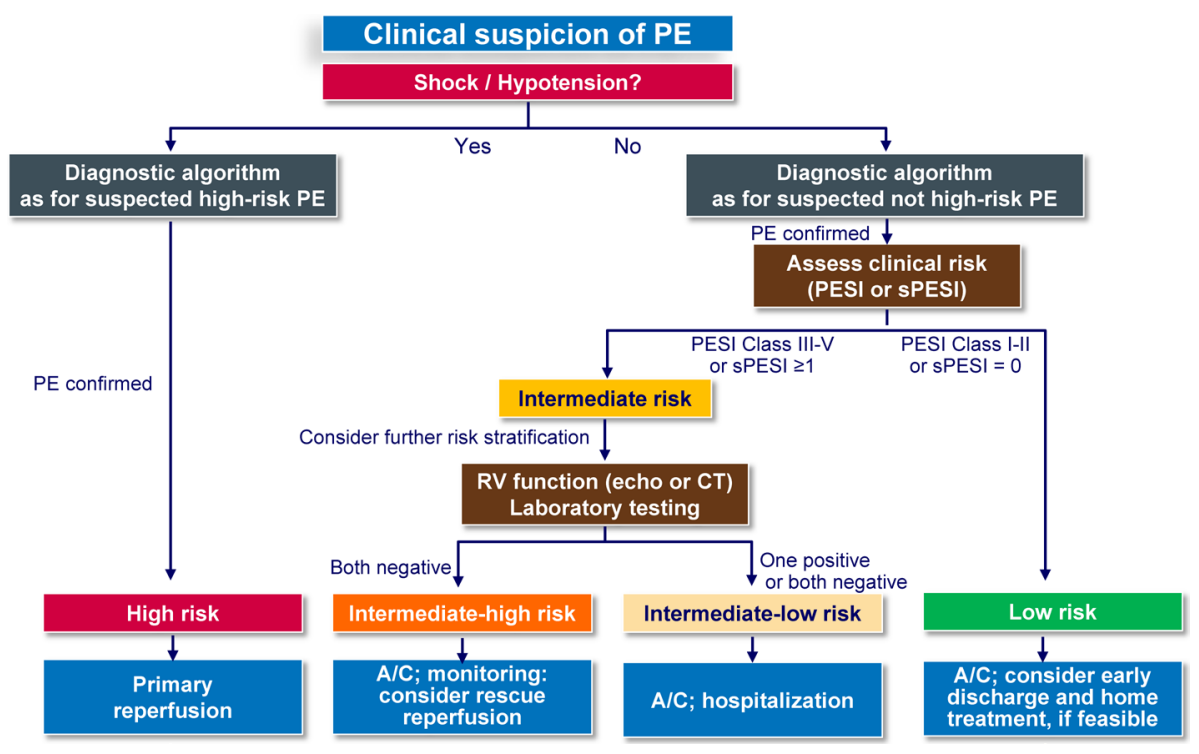

Fig. 1 Integrated risk-adjusted management algorithm for acute pulmonary embolism (Reproduced from reference 7 by permission of Oxford University Press).

A/C: anticoagulation; CT: computed tomographic; PE: pulmonary embolism; PESI: Pulmonary Embolism Severity Index; RV: right ventricular; sPESI: simplified Pulmonary Embolism Severity Index

Konstantinides SV, et al. 2014 ESC Guidelines on the diagnosis and management of acute pulmonary embolism. European Heart Journal 2014; 35 (43): 3033-3080, doi:10.1093/eurheartj/ehu283. Reproduced by permission of Oxford University Press on behalf of the European Society of Cardiology. (c) European Society of Cardiology 2014. All rights reserved. For permissions please email: journals.permissions@oup.com Please visit: www.escardio.org/Guidelines/Clinical-Practice-Guidelines/Acute-PulmonaryEmbolism-Diagnosis-and-Management-of This figure is not include under the Creative Commons license of this publication.

Table 1 Risk categories in patients with acute pulmonary embolism

\begin{tabular}{lccccc}
\hline & Early mortality risk & \multicolumn{3}{c}{ Risk parameters and scores } \\
\cline { 3 - 5 } & $\begin{array}{c}\text { Shock or } \\
\text { hypotension }\end{array}$ & $\begin{array}{c}\text { PESI class III-V or } \\
\text { sPESI } \geq 1\end{array}$ & $\begin{array}{c}\text { Signs of RV dysfunction } \\
\text { on an imaging test }\end{array}$ & $\begin{array}{c}\text { Cardiac laboratory } \\
\text { biomarkers }\end{array}$ \\
\hline High & Intermediate-high & - & $(+)$ & + & Both positive \\
Intermediate & Intermediate-low & - & $(+)^{*}$ & Either one (or none) positive \\
Low & - & - & Assessment optional; if assessed, both negative \\
\hline
\end{tabular}

From the 2014 European Society of Cardiology Guidelines on the Diagnosis and Management of Pulmonary Embolism, updated (Reproduced from reference 18 by permission of Oxford University Press.)

* The current guidelines do not routinely recommend further assessment in patients belonging to the PESI class I-II, or with a sPESI of 0 . Nevertheless, some of these patients have been reported to exhibit RV dysfunction on imaging tests and/or elevated biomarker levels. If any doubts persist regarding the severity of PE upon clinical evaluation of the patient, even in the presence of a formally low PESI or a SPESI of 0 , the functional status of the RV should be assessed. If RV dysfunction is then detected, the patients' risk should be classified based on the imaging and biochemical tests. PESI: Pulmonary Embolism Severity Index; RV: right ventricular

Konstantinides SV, et al. 2014 ESC Guidelines on the diagnosis and management of acute pulmonary embolism. European Heart Journal 2014; 35 (43): 3033-3080, doi:10.1093/eurheartj/ehu283. Reproduced by permission of Oxford University Press on behalf of the European Society of Cardiology. (c) European Society of Cardiology 2014. All rights reserved. For permissions please email: journals.permissions@oup.com Please visit: www.escardio.org/Guidelines/Clinical-Practice-Guidelines/Acute-Pulmonary-Embolism-Diagnosis-andManagement-of This figure is not include under the Creative Commons license of this publication.

The high-risk group represents $5 \%$ only or even less of all PE patients. ${ }^{1,8)}$ Outside this emergency situation, normotensive, "not-high-risk PE" patients should be stratified further into intermediate versus low risk using two categories of tools or modalities: (i) the Pulmonary Embolism Severity Index (PESI), or its simplified form (sPESI), reflecting clinical severity and comorbidity; and (ii) imaging and/or laboratory tests detecting subclinical right ventricular dysfunction or myocardial injury. ${ }^{7)}$ While PESI and sPESI serve primarily to identify low-risk patients who may be eligible for early discharge and home treatment, echocardiographic (or computed tomographic) or 
biochemical markers of right ventricular (RV) dysfunction represent the key tool for defining the groups of "intermediate-low risk" (with either evidence of RV dysfunction or elevated biochemical markers) or "intermediate-high risk" (with RV dysfunction combined with elevated biochemical markers) (Table 1). This advanced classification helps to determine the need for hemodynamic monitoring as well as the need for (rescue) reperfusion treatment. In addition, it may be helpful for the choice of the initial anticoagulant regimen, as will be explained below.

\section{Management of Acute Right Heart Failure}

Recently, a statement from the Heart Failure Association and the Working Group on Pulmonary Circulation and Right Ventricular Function of the European Society of Cardiology reviewed the principles of acute right heart failure management. ${ }^{9)}$ Acute RV failure responds to changes in preload; however, excessive volume loading may increase wall tension, may decrease contractility, and may impair left ventricular filling. The most reasonable approach is cautious volume loading guided by central venous pressure monitoring and aimed at reaching and maintaining pressures of 5 to (maximally) $10 \mathrm{mmHg}$.

Vasopressors, particularly noradrenaline, are preferred in shock because they restore the blood pressure and improve cerebral, coronary, and other organ perfusion, without disproportionately increasing pulmonary vascular resistance. By combining RV inotropy and pulmonary vasodilation, levosimendan appears to have a favorable hemodynamic profile, even though the evidence to support its use in precapillary RV failure (i.e., not due to left heart disease) is not very strong yet. In addition, phosphodiesterase III inhibitors are expected to exert positive inotropic effects on the RV without increasing pulmonary vascular resistance; however, like dobutamine, they may aggravate arterial hypotension and, therefore, should be combined with noradrenaline if used. Finally, mechanical circulatory support of the RV, including extracorporeal membrane oxygenation (ECMO) or life support (ECLS), may be required in acute high-risk PE. Timely implantation is critical to avoid irreversible organ damage and, thus, the early transfer of the patient to an expert referral center is essential.

\section{Reperfusion Therapies}

\section{Systemic intravenous thrombolysis}

Since the late 1960s, thrombolytic agents have been used for the treatment of acute PE. ${ }^{10)}$ Today, immediate systemic reperfusion treatment with intravenous thrombolysis continues to be the mainstay of therapy for high-risk (or massive) PE. ${ }^{7,11,12)}$ This recommendation is supported by meta-analyses of randomized trials, which suggested that thrombolysis may reduce, by approximately two-thirds, early mortality or hemodynamic decompensation requiring further "rescue" treatment. ${ }^{13)}$ Of course, this benefit may be counterbalanced by the risk of major bleeding, which occurs much more frequently than under anticoagulation alone (odds ratio (OR) 2.91, 95\% confidence interval $(\mathrm{CI})$ : $1.95-4.36)$, particularly when fatal or intracranial hemorrhage is considered (OR 3.18, 95\% CI: 1.25-8.11). ${ }^{13)}$ In the light of this delicate balance, current guidelines point out that intermediate- or low-risk patients with acute PE are not likely to benefit from the routine use of systemic thrombolysis and that, therefore, this treatment should (only) be used as rescue treatment in case of hemodynamic decompensation under anticoagulation alone. ${ }^{7,12)}$ the results of the Pulmonary Embolism Thrombolysis (PEITHO) trial, which compared a single bolus of tenecteplase (plus heparin) with placebo (plus heparin) in 1,006 patients with acute PE and RV dysfunction plus myocardial injury detected by imaging and a positive cardiac troponin test have provided the basis for this recommendation; in this intermediate-high-risk group (Table 1), the clinical benefits of thrombolysis were outweighed by the intracranial and other major bleeding risk. ${ }^{14}$

Emerging approaches to the reperfusion treatment of PE might help to achieve comparable efficacy while minimizing the bleeding risk associated with systemic (intravenous) full-dose thrombolysis. Preliminary evidence from small studies suggests that reduced-dose systemic thrombolysis might represent an option for improving safety while maintaining the efficacy of this treatment. In a prematurely terminated trial of 118 patients, half-dose recombinant tissue-type plasminogen activator (alteplase) was comparable to the full dose in terms of efficacy and possibly associated with improved safety ${ }^{15}$; in another study of 121 patients with "moderate PE," reduced-dose recombinant tissue plasminogen activator ( $\mathrm{rtPA}$ ) appeared to be safe and effective over a follow-up period of more than two years. ${ }^{16)}$ However, at the moment, until the hypothesis generated by these data is confirmed by larger, appropriately designed trials with standardized selection criteria and outcomes, the use of "low-dose" thrombolytic regimens cannot be proposed as an alternative to the dosage approved for systemic (intravenous) use.

\section{Pharmacomechanical, catheter-directed reperfu- sion}

Catheter-directed pharmacomechanical reperfusion with low-dose local thrombolysis has been developed as an option for clearing pulmonary thrombi from the larger arteries $^{17)}$; this procedure is an alternative to operative embolectomy if systemic thrombolysis is contraindicated or the bleeding risk is high. ${ }^{\text {7) }} \mathrm{A}$ phase-2 randomized multicenter 
trial enrolled patients with acute PE and a right-to-left ventricular dimension ratio $\geq 1.0$, comparing unfractionated heparin plus a 15 -hour catheter-directed, ultrasoundassisted regimen of 10-20 mg rtPA versus heparin alone. ${ }^{18)}$ Catheter-directed treatment led to significant recovery of the RV function at $24 \mathrm{~h}$, with no increased risk of major hemorrhage. ${ }^{18)}$ The efficacy and safety of the pharmacomechanical approach using low dose local thrombolysis was more recently supported by the results of a prospective, single-arm multicenter trial, ${ }^{19)}$ and those of a registry, both including patients with massive or submassive PE. ${ }^{20)}$ Of course, and like every interventional procedure, catheterdirected pharmacomechanical reperfusion requires adequate operator expertise and institutional volume. Furthermore, it remains to be determined whether the speed of thrombus removal and, consequently, of the relief of the $\mathrm{RV}$ from pressure overload, is adequately high in patients with overt or imminent hemodynamic decompensation, and whether the use of ultrasound is really necessary for obtaining maximum efficacy. ${ }^{18)}$

\section{Pulmonary Embolism Response Teams}

A timely PE diagnosis and risk-adapted advanced treatment determine the outcome of patients within the first days after acute PE. ${ }^{7,12,21)}$ Off-hour admissions for acute PE have been associated with a significant increase in mortality, ${ }^{22)}$ and PE patients admitted over weekends may have a worse prognosis than individuals admitted during weekdays do. ${ }^{23}$ ) To improve the acute management of patients with severe acute PE patients, a new multidisciplinary decision-making paradigm, the Pulmonary Embolism Response Team (PERT), was developed. ${ }^{24)}$ Currently, many institutions are in the process of creating PERTs for the coordination of the different specialists potentially involved in the management of "severe PE" cases, including decisions regarding the use of catheter-directed reperfusion techniques. ${ }^{25,26)}$ Importantly, the PERT models proposed can be adapted for implementation both in academic medical centers and in community hospitals. ${ }^{21,24,26,27)}$

\section{Uncertainty over the impact of thrombolysis on late outcomes after pulmonary embolism}

A substantial proportion of patients who have survived an acute PE episode may complain of persistent functional limitation and/or reduced quality of life for long periods after the index event. ${ }^{2)}$ Moreover, some degree of persistent pulmonary hypertension or RV dysfunction was observed in as many as $40 \%$ of survivors followed over 6 months to one year after acute PE. ${ }^{28)}$ Since the number of patients followed in observational studies performed so far was rather small, echocardiographic parameters of RV dysfunction were not standardized, and a correlation of ultrasound findings with the severity of patients' symptoms or the degree of functional limitation could not be established, these data are to be interpreted with caution. ${ }^{29)}$

Many clinicians believe that early thrombolysis may favorably affect the patients' long-term prognosis after PE. Two small randomized trials suggested that thrombolysis might improve, compared to anticoagulation alone, the patients' functional capacity at 3 months, ${ }^{30)}$ or the persistence (or development) of pulmonary hypertension at 28 months. ${ }^{16)}$ On the other hand, the two-year follow-up of intermediate-risk patients randomized to tenecteplase plus anticoagulation versus anticoagulation alone in the PEITHO trial ${ }^{14)}$ revealed no impact of thrombolytic therapy on the overall survival rates after acute PE. ${ }^{31)}$ Therefore, to date, the treatment of acute right ventricular failure and helping the unstable patient to survive the first few hours or days after acute PE remains the main indication for thrombolytic treatment.

\section{Anticoagulation for Acute Treatment and Secondary Prophylaxis}

\section{Shift towards the new, direct oral anticoagulants as the standard of care}

In all patients with acute PE, to reduce the risk of recurrence and fatal thromboembolic events, anticoagulation treatment should be initiated immediately. In fact, the first dose of anticoagulant treatment, preferably, one subcutaneous injection of low-molecular-weight heparin or fondaparinux, should be given already during the diagnostic workup in patients having an intermediate or high clinical "pre-test" probability of PE, i.e., even before the disease is confirmed by an imaging test. ${ }^{7)}$ High-risk individuals with hemodynamic instability, or in whom clinical decompensation is considered imminent, may be candidates for thrombolytic or other reperfusion treatment and, therefore, should initially receive an intravenous agent with a shorter half-life (unfractionated heparin) and the possibility of a laboratory monitoring of the anticoagulant levels.

For many years, parenteral anticoagulant agents (heparins or the synthetic pentasaccharide fondaparinux) followed by vitamin $\mathrm{K}$ antagonists (VKA) represented the gold standard for the anticoagulant treatment of VTE. The standard regimen consisted of parenteral anticoagulation and VKA co-administration for the first 5-10 days, until the International Normalized Ratio (INR) values reached the target therapeutic range (between 2.0 and 3.0 or, in Japan, between 1.5 and 2.5) for at least two consecutive days; then, heparin was discontinued. This strategy is still valid and is included in the guideline recommendations; however, in the past decade, two classes of direct, nonvitamin K-dependent oral anticoagulants (NOACs) were 
approved for the treatment and secondary prophylaxis of acute PE: three direct factor-Xa inhibitors (rivaroxaban, apixaban, edoxaban), and one direct thrombin inhibitor (dabigatran). These drugs exhibit similarly short half-lives (7 to $13 \mathrm{~h}$ ) and a predictable anticoagulant effect allow- ing fixed dose administration with no need for routine monitoring. Large phase III trials showed that these drugs were non-inferior to the "standard" treatment mentioned above with respect to efficacy outcomes, while their safety profile was superior to that of the comparator arm, par-

Table 2 Overview of non-vitamin K-dependent oral anticoagulants in the acute-phase treatment and secondary prevention of pulmonary embolism and deep vein thrombosis

\begin{tabular}{|c|c|c|c|c|}
\hline \multirow{2}{*}{ Anticoagulant } & \multicolumn{3}{|c|}{ Dosage and anticoagulation period } & \multirow{2}{*}{ Not recommended or contraindicated* } \\
\hline & Initial & Long-term & Extended & \\
\hline \multirow[t]{3}{*}{ Rivaroxaban } & $15 \mathrm{mg}$ twice daily for & \multirow{3}{*}{\multicolumn{2}{|c|}{$\begin{array}{l}20 \mathrm{mg} \text { once daily with food ( } 15 \mathrm{mg} \text { once } \\
\left.\text { daily in selected patients }{ }^{\dagger}\right) 15 \mathrm{mg} \text { once } \\
\text { daily in Japan }\end{array}$}} & $\cdot \mathrm{CrCl}<30 \mathrm{~mL} / \mathrm{min}(\mathrm{FDA}), \mathrm{CrCl}<15 \mathrm{~mL} / \mathrm{min}(\mathrm{EMA})$ \\
\hline & 21 days & & & $\begin{array}{l}\text { Moderate or severe hepatic impairment (Child- } \\
\text { Pugh B and C), or hepatic disease associated with } \\
\text { coagulopathy }\end{array}$ \\
\hline & & & & $\begin{array}{l}\text { Concomitant use of combined P-gp and strong } \\
\text { CYP3A4 inhibitors or inducers }\end{array}$ \\
\hline \multirow{3}{*}{$\begin{array}{l}\text { Dabigatran } \\
\text { etexilate }^{* *}\end{array}$} & \multirow{3}{*}{$\begin{array}{l}\text { Initial therapy } \\
\text { with parenteral } \\
\text { anticoagulation for } \\
5-10 \text { days }\end{array}$} & \multirow{3}{*}{\multicolumn{2}{|c|}{$\begin{array}{l}150 \mathrm{mg} \text { twice daily ( } 110 \mathrm{mg} \text { twice daily in } \\
\text { selected patients } \ddagger \text { ) }\end{array}$}} & $\cdot \mathrm{CrCl}<30 \mathrm{~mL} / \mathrm{min}$ \\
\hline & & & & $\begin{array}{l}\text { Elevated liver enzymes }>2 \times \text { upper limit of normal } \\
\text { or with liver disease expected to have an impact on } \\
\text { survival }\end{array}$ \\
\hline & & & & $\begin{array}{l}\text { Concomitant treatment with P-gp inhibitors in pa- } \\
\text { tients with } \mathrm{CrCl}<50 \mathrm{~mL} / \mathrm{min} \text { or with P-gp inducers } \\
\text { (i.e., rifampin) }\end{array}$ \\
\hline \multirow[t]{3}{*}{ Apixaban } & \multirow{3}{*}{$\begin{array}{l}10 \mathrm{mg} \text { twice daily for } \\
7 \text { days }\end{array}$} & \multirow[t]{3}{*}{$5 \mathrm{mg}$ twice daily } & \multirow{3}{*}{$\begin{array}{l}2.5 \mathrm{mg} \text { twice daily } \\
\text { after at least } 6 \\
\text { months of treatment }\end{array}$} & $\cdot \mathrm{CrCl}<15 \mathrm{~mL} / \mathrm{min}$ \\
\hline & & & & $\begin{array}{l}\text { Severe hepatic impairment (Child-Pugh C), or he- } \\
\text { patic disease associated with coagulopathy }\end{array}$ \\
\hline & & & & $\begin{array}{l}\text { Strong dual inhibitors or inducers of CYP3A4 and } \\
\text { P-gp }\end{array}$ \\
\hline \multirow[t]{3}{*}{ Edoxaban§ } & \multirow{3}{*}{$\begin{array}{l}\text { Initial therapy } \\
\text { with parenteral } \\
\text { anticoagulation for } \\
5-10 \text { days }\end{array}$} & \multirow{3}{*}{\multicolumn{2}{|c|}{$\begin{array}{l}60 \mathrm{mg} \text { once daily ( } 30 \mathrm{mg} \text { once daily in } \\
\text { selected patients } \$ \text { ) }\end{array}$}} & $\cdot \mathrm{CrCl}<15 \mathrm{~mL} / \mathrm{min}$ \\
\hline & & & & $\begin{array}{l}\text { - Moderate or severe hepatic impairment (Child- } \\
\text { Pugh B and C), or hepatic disease associated with } \\
\text { coagulopathy }\end{array}$ \\
\hline & & & & Concomitant treatment with rifampin \\
\hline
\end{tabular}

The Table is adapted from reference 50 .

CrCl: creatinine clearance; CYP3A4: cytochrome P450-3A4; EMA: European Medicines Agency; FDA: Food and Drug Administration (United States); NSAID: nonsteroidal anti-inflammatory drug(s); P-gp: P-glycoprotein; VTE: venous thromboembolism

*All the mentioned anticoagulant agents should also be avoided in patients: 1) for whom thrombolysis or pulmonary embolectomy may be required; 2) requiring dialysis; 3) at significant risk of bleeding; 4) receiving a concomitant anticoagulant; 5) with known hypersensitivity to the agent, and 6) during pregnancy or breastfeeding.

${ }^{\dagger}$ According to the EMA product information, rivaroxaban $15 \mathrm{mg}$ should be considered for the long-term phase if the patient's assessed risk for bleeding outweighs the risk for recurrent venous thromboembolism. In the European Union, rivaroxaban is contraindicated in patients with $\mathrm{CrCl}<15 \mathrm{~mL} / \mathrm{min}$ and should be used with caution in patients with $\mathrm{CrCl} 15-30 \mathrm{~mL} / \mathrm{min}$.

$\ddagger$ According to the EMA product information, dabigatran $110 \mathrm{mg}$ twice daily is recommended in patients aged 80 years or above and in those receiving concomitant verapamil, while it can be considered in patients between 75 and 80 years, with moderate renal impairment, with gastritis, esophagitis or gastroesophageal reflux, or in other subjects at increased risk of bleeding.

§Although a separate extension trial was not conducted for edoxaban, more than $40 \%$ of patients included in the Hokusai-VTE study received treatment with edoxaban for up to 12 months. The reduced daily dose $(30 \mathrm{mg})$ should be considered in patients with $\geq 1$ of the following: $\mathrm{CrCl} 15-50 \mathrm{~mL} / \mathrm{min}$; body weight $\leq 60 \mathrm{~kg}$; concomitant use of P-gp inhibitors, cyclosporin, dronedarone, erythromycin, or ketoconazole.

** Not approved in Japan for the treatment of acute venous thromboembolism.

Konstantinides SV, et al. 2014 ESC Guidelines on the diagnosis and management of acute pulmonary embolism. European Heart Journal 2014; 35 (43): 3033-3080, doi:10.1093/eurheartj/ehu283. Reproduced by permission of Oxford University Press on behalf of the European Society of Cardiology. (c) European Society of Cardiology 2014. All rights reserved. For permissions please email: journals. permissions@oup.com Please visit: www.escardio.org/Guidelines/Clinical-Practice-Guidelines/Acute-Pulmonary-Embolism-Diagnosis-andManagement-of This figure is not include under the Creative Commons license of this publication. 
Table 3 Ongoing trials on specific patient populations and possible new or extended indications of NOACs for the treatment or secondary prevention of deep vein thrombosis or pulmonary embolism

\begin{tabular}{|c|c|c|c|c|c|c|c|c|}
\hline Study identifier & Population & Intervention & Comparator & $\begin{array}{l}\text { Primary clinical } \\
\text { outcome(s) }\end{array}$ & Follow-up & $\begin{array}{l}\text { Sample } \\
\text { size }\end{array}$ & Study & $\begin{array}{c}\text { Estimated } \\
\text { completion date }\end{array}$ \\
\hline $\begin{array}{l}\text { НоT-PE } \\
(2013-001657-28)\end{array}$ & $\begin{array}{l}\text { Outpatient management } \\
\text { of acute PE }\end{array}$ & $\begin{array}{l}\text { Rivaroxaban standard } \\
\text { therapeutic dose }\end{array}$ & - & $\begin{array}{l}\text { Recurrent VTE or } \\
\text { PE-related death }\end{array}$ & 3 months & 1,100 & Phase 4 & January 2019 \\
\hline $\begin{array}{l}\text { RIDTS } \\
\text { (NCT02722447) }\end{array}$ & Isolated distal DVT & $\begin{array}{l}\text { Rivaroxaban standard } \\
\text { therapeutic dose for } 6 \\
\text { weeks after an initial } \\
\text { course of 6-week } \\
\text { treatment }\end{array}$ & Placebo & Recurrent VTE & 3 months & 1,100 & Phase 3b & June 2020 \\
\hline $\begin{array}{l}\text { VERDICT } \\
\text { (NCT02664155) }\end{array}$ & $\begin{array}{l}\text { Acute VTE in patients } \\
\text { with moderate or se- } \\
\text { vere renal dysfunction }\end{array}$ & $\begin{array}{l}\text { Apixaban standard } \\
\text { therapeutic dose for } \\
7 \text { days followed by } \\
2.5 \mathrm{mg} \text { twice daily, or } \\
\text { rivaroxaban standard } \\
\text { therapeutic dose for } \\
21 \text { days followed by } \\
15 \mathrm{mg} \text { once daily }\end{array}$ & $\begin{array}{l}\text { Standard of care } \\
\text { (heparin, INR- } \\
\text { adjusted VKA) }\end{array}$ & $\begin{array}{l}\text { Net clinical benefit } \\
\text { (recurrent VTE, major } \\
\text { bleeding) }\end{array}$ & 3 months & 800 & Phase 3b & March 2019 \\
\hline $\begin{array}{l}\text { PEITHO-2 } \\
\text { (NCT02596555) }\end{array}$ & Intermediate risk $\mathrm{PE}$ & $\begin{array}{l}\text { LMWH standard } \\
\text { therapeutic dose } \\
\text { for } 72 \mathrm{~h} \text { followed by } \\
\text { dabigatran standard } \\
\text { therapeutic dose }\end{array}$ & - & $\begin{array}{l}\text { Recurrent VTE or } \\
\text { PE-related death }\end{array}$ & 6 months & 700 & Phase 4 & August 2019 \\
\hline $\begin{array}{l}\text { TRAPS } \\
\text { (NCT02157272) }\end{array}$ & $\begin{array}{l}\text { Antiphospholipid } \\
\text { syndrome }\end{array}$ & $\begin{array}{l}\text { Rivaroxaban standard } \\
\text { therapeutic dose }\end{array}$ & $\begin{array}{l}\text { INR-adjusted } \\
\text { warfarin }\end{array}$ & $\begin{array}{l}\text { Recurrent thrombosis, } \\
\text { major bleeding, death }\end{array}$ & 4 years & 536 & Phase 3b & December 2018 \\
\hline $\begin{array}{l}\text { SECRET } \\
(\text { NCT03178864) }\end{array}$ & $\begin{array}{l}\text { Cerebral venous } \\
\text { thrombosis }\end{array}$ & $\begin{array}{l}\text { Rivaroxaban standard } \\
\text { therapeutic dose }\end{array}$ & Standard of care & $\begin{array}{l}\text { Death, intracranial } \\
\text { bleeding, major } \\
\text { bleeding }\end{array}$ & 6 months & 384 & Phase 2 & June 2020 \\
\hline $\begin{array}{l}\text { Apixaban: VTE } \\
\text { treatment in cancer } \\
\text { (NCT02585713) }\end{array}$ & $\begin{array}{l}\text { Cancer patients with } \\
\text { acute VTE }\end{array}$ & $\begin{array}{l}\text { Apixaban standard } \\
\text { therapeutic dose }\end{array}$ & $\begin{array}{l}\text { Dalteparin standard } \\
\text { therapeutic dose }\end{array}$ & Major bleeding & 6 months & 315 & Phase $3 b$ & December 2020 \\
\hline $\begin{array}{l}\text { RAMBLE } \\
\text { (NCT02761044) }\end{array}$ & $\begin{array}{l}\text { Treatment of VTE in } \\
\text { young women }\end{array}$ & $\begin{array}{l}\text { Rivaroxaban standard } \\
\text { therapeutic dose }\end{array}$ & $\begin{array}{l}\text { Apixaban standard } \\
\text { therapeutic dose }\end{array}$ & $\begin{array}{l}\text { Patient reported } \\
\text { menstrual bleeding }\end{array}$ & 3 months & 308 & Phase 3b & May 2019 \\
\hline $\begin{array}{l}\text { CAP } \\
\text { (NCT02581176) }\end{array}$ & $\begin{array}{l}\text { Cancer patients with } \\
\text { acute VTE }\end{array}$ & $\begin{array}{l}\text { Apixaban standard } \\
\text { therapeutic dose for } \\
6 \text { months followed by } \\
2.5 \mathrm{mg} \text { twice daily }\end{array}$ & - & $\begin{array}{l}\text { Recurrent VTE, major } \\
\text { or clinically relevant } \\
\text { non-major bleeding }\end{array}$ & 6 months & 300 & Phase 4 & January 2021 \\
\hline $\begin{array}{l}\text { CASTA-DIVA } \\
\text { (NCT02746185) }\end{array}$ & $\begin{array}{l}\text { Cancer patients with } \\
\text { acute VTE }\end{array}$ & $\begin{array}{l}\text { Rivaroxaban standard } \\
\text { therapeutic dose }\end{array}$ & $\begin{array}{l}\text { Dalteparin standard } \\
\text { therapeutic dose }\end{array}$ & Recurrent VTE & 6 months & 200 & Phase 3b & May 2017 \\
\hline $\begin{array}{l}\text { ASTRO-APS } \\
\text { (NCT02295475) }\end{array}$ & $\begin{array}{l}\text { Antiphospholipid } \\
\text { syndrome }\end{array}$ & $\begin{array}{l}\text { Apixaban } 5 \mathrm{mg} \\
\text { twice daily }\end{array}$ & $\begin{array}{l}\text { INR-adjusted } \\
\text { warfarin }\end{array}$ & $\begin{array}{l}\text { Recurrent thrombosis, } \\
\text { major and non-major } \\
\text { bleeding }\end{array}$ & $\begin{array}{l}13 \\
\text { months }\end{array}$ & 200 & Phase 3b & December 2017 \\
\hline $\begin{array}{l}\text { RE-SPECT CVT } \\
\text { (NCT02913326) }\end{array}$ & $\begin{array}{l}\text { Cerebral vein throm- } \\
\text { bosis }\end{array}$ & Dabigatran etexilate & $\begin{array}{l}\text { INR-adjusted } \\
\text { warfarin }\end{array}$ & $\begin{array}{l}\text { Major bleeding, } \\
\text { venous thrombosis }\end{array}$ & 6 months & 120 & Phase 3 & July 2020 \\
\hline $\begin{array}{l}\text { MERCURY PE } \\
(\text { NCT02584660) }\end{array}$ & $\begin{array}{l}\text { Outpatient management } \\
\text { of acute PE }\end{array}$ & $\begin{array}{l}\text { Rivaroxaban standard } \\
\text { therapeutic dose }\end{array}$ & Standard of care & $\begin{array}{l}\text { Major bleeding, days } \\
\text { of hospitalization }\end{array}$ & 3 months & 120 & Phase 3b & March 2017 \\
\hline $\begin{array}{l}\text { RIVASVT-100 } \\
\text { (NCT02627053) }\end{array}$ & $\begin{array}{l}\text { Treatment of acute } \\
\text { portal, mesenteric or } \\
\text { splenic vein thrombosis }\end{array}$ & $\begin{array}{l}\text { Rivaroxaban standard } \\
\text { therapeutic dose }\end{array}$ & - & Major bleeding & 3 months & 100 & Phase 4 & December 2018 \\
\hline
\end{tabular}

DVT: deep vein thrombosis; NOAC: non-vitamin K-dependent oral anticoagulant(s); PE: pulmonary embolism; VTE: venous thromboembolism

Study acronyms (where available): ASTRO-APS: Apixaban for the Secondary prevention of ThROmboembolism among patients with the AntiPhospholipid Syndrome; CASTA-DIVA: Cancer ASsociated Thrombosis, A pilot treatment stuDy using rIVAroxaban; HoT-PE: Home Treatment of patients with low-risk Pulmonary Embolism; MERCURY PE: MulticEnter trial of Rivaroxaban for early disCharge of pUImonaRY embolism from the Emergency Department; PEITHO-2: Pulmonary Embolism International Trial-2; RAMBLE: Rivaroxaban vs Apixaban on Menstrual Blood Loss; RE-SPECT CVT: A Clinical Trial Comparing Efficacy and Safety of Dabigatran Etexilate With Warfarin in Patients With Cerebral Venous and Dural Sinus Thrombosis; RIDTS: RIvaroxaban for the treatment of symptomatic Isolated Distal Deep vein ThrombosiS; RIVASVT-100: RIVAroxaban for the treatment of Splanchnic Vein Thrombosis; SECRET: Study of rivaroxaban for CeREbral venous Thrombosis; TRAPS: Trial on Rivaroxaban in high risk patients with AntiPhospholipid Syndrome; VERDICT: VEnous thromboembolism in Renally impaired patients and DIreCT oral anticoagulants 
ticularly in terms of major bleeding. ${ }^{32,33)}$ The results of parallel trials conducted in Japanese patients diagnosed with acute DVT and/or PE suggested similar efficacy and safety of NOACs consistent with what was observed in the international phase III trials. ${ }^{34,35)}$ Moreover, subgroup analyses and meta-analyses focusing on Japanese (or East Asian) patients provided a broader confirmation of these findings. ${ }^{36-38)}$ The J-EINSTEIN DVT and PE trials used a lower dosage of rivaroxaban that in the global trial on the basis of pharmacokinetic data. On the other hand, the sub-studies performed within the Hokusai-VTE trial (edoxaban) and the AMPLIFY-J trial (apixaban) adopted similar regimens. ${ }^{34,36,38)}$ No data from phase III trial regarding the use of dabigatran are available for the treatment of acute VTE in the Japanese population, and this drug did not receive approval for this indication; it can be used for the prevention of embolic complications in patients with atrial fibrillation. ${ }^{39}$

Accumulating "real-world" data appear to confirm the results of the large phase 3 trials regarding the efficacy and safety of NOACs. ${ }^{40)}$ Consequently, NOACs are increasingly being used in the treatment of VTE worldwide. Table 2 summarizes the approved regimens of the NOACs for the initial, long-term, and extended management of acute PE. Table 3 displays a list of major ongoing NOAC trials on specific patient populations, treatment duration, and possible new or extended indications.

Although NOACs are generally associated with less frequent life-threatening complications compared to VKA, prediction of the bleeding risk and the management of bleeding under an anticoagulant drug remains a major challenge. Bleeding scores which have been derived from patients with atrial fibrillation generally perform poorly in patients with VTE who are under chronic anticoagulation;

Table 4 The VTE-BLEED score for prediction of major bleeding events during stable anticoagulation after VTE

\begin{tabular}{|c|c|}
\hline Baseline variable & Score \\
\hline Active cancer ${ }^{a}$ & 2 \\
\hline Male patient with uncontrolled arterial hypertension ${ }^{b}$ & 1 \\
\hline Anemiac & 1.5 \\
\hline History of bleeding ${ }^{d}$ & 1.5 \\
\hline Age $\geq 60$ years old & 1.5 \\
\hline Renal dysfunctione & 1.5 \\
\hline \multicolumn{2}{|l|}{ Classification of bleeding risk* } \\
\hline Low risk & Total score $<2$ \\
\hline High risk & Total score $\geq 2$ \\
\hline
\end{tabular}

* Refers to the risk of major or clinically relevant non-major bleeding. ${ }^{63)}$

eGFR: estimated glomerular filtration rate; VTE: venous thromboembolism

Definition of score variables in the derivation population ${ }^{63,64)}$ : aCancer diagnosed within 6 months before diagnosis of VTE (excluding basal-cell or squamous-cell carcinoma of the skin), recently recurrent or progressive cancer, or any cancer that required anti-cancer treatment within 6 months before the VTE was diagnosed; b Uncontrolled arterial hypertension defined as systolic blood pressure $\geq 140 \mathrm{mmHg}$ at baseline; ${ }^{\circ}$ Hemoglobin $<13 \mathrm{~g} / \mathrm{dL}$ in men or $<12 \mathrm{~g} / \mathrm{dL}$ in women; ${ }^{\mathrm{d}}$ Including prior major or non-major clinically relevant bleeding event, rectal bleeding, frequent nose bleeding, or hematuria; e eGFR $<60 \mathrm{~mL} / \mathrm{min}$ at baseline, calculated using with the Cockcroft-Gault formula which accounts for serum creatinine, age, and body weight.

Table 5 Instructions on NOAC reversal in emergency situations

Indications for use of NOAC reversal agents

Potential indication for use of NOAC reversal agents

Reversal agents not indicated
-Life-threatening bleeding (i.e., intracranial hemorrhage)

-Bleeding in a closed space or critical organ (intraspinal, intraocular, pericardial, pulmonary, retroperitoneal, or intramuscular with compartment syndrome)

- Major bleeding not responsive to local hemostatic measures or risk of recurrent bleeding because of delayed NOAC clearance or NOAC overdose

-Need for emergency surgery or intervention that is associated with a high risk of bleeding

-Emergency surgery or intervention in patients at high risk for procedural bleeding: neurosurgery (intracranial, extradural, or spinal), lumbar puncture, cardiac or vascular surgery (aortic dissection/aneurysm repair), hepatic or other major organ surgery

-Need for urgent surgery or intervention in patients with acute renal failure

-Elective surgery

Gastrointestinal bleeds that respond to supportive measures

-High drug levels or excessive anticoagulation without associated bleeding

-Need for surgery or intervention that can be delayed long enough to permit drug clearance

-Institutional protocol for management of bleeding in patients taking anticoagulants

- Dedicated logistics for storage and timely administration of the antidote

-Team approach to manage bleeding complications in anticoagulated patients

This Table is in accordance with the recent recommendations issued by the International Society on Thrombosis and Haemostasis. ${ }^{44)}$ 
however, a recently developed score (Table 4) appears to be more promising and helpful. ${ }^{41)}$

The reversal of NOAC effects if bleeding occurs is perceived as an important need among clinicians and, thus, it continues to be the subject of intense clinical investigation. Idarucizumab, a reversal agent ("antidote") for the direct thrombin inhibitor dabigatran has already been approved and is available for clinical use; this agent has been integrated in recently updated bleeding management algorithms. ${ }^{42)}$ Andexanet, a reversal agent against the direct oral factor Xa inhibitors apixaban and rivaroxaban (and possibly also against edoxaban as well as the low molecular weight heparin enoxaparin as an indirect parenteral Xa inhibitor), has yielded promising results in an ongoing phase 3 clinical trial ${ }^{43)}$ and will probably also be approved in the future. Ciraparantag, a synthetic cationic small molecule and "universal" antidote is at an earlier stage of development. In view of the concerns regarding the potential for overuse or misuse of antidotes in clinical practice, the International Society on Thrombosis and Haemostasis (ISTH) has issued recommendations regarding their indications and contraindications together with handling instructions ${ }^{44)}$; Table 5 summarizes these.

\section{Extending the duration of anticoagulant treatment for secondary prophylaxis of VTE}

The duration of anticoagulation after a first episode of VTE should cover a minimum of 3 months; however, it remains largely undetermined beyond that time and, therefore, is frequently individualized on a case by case basis. ${ }^{7}{ }^{12)}$ It is an undisputed fact that the VTE recurrence risk begins to rise as soon as anticoagulation is discontinued, regardless of its previous duration. Recently, this finding was confirmed by the PADIS-PE study, a randomized double-blind trial of 371 patients diagnosed with a first symptomatic unprovoked PE. In this study, the authors compared the rate of recurrence or major bleeding in patients treated with warfarin for 18 months (following the first course of 6-month treatment) vs patients receiving no extended warfarin treatment. ${ }^{45}$ ) The results showed clearly that the benefit observed in the group receiving extended treatment in terms of recurrence prevention was not maintained after anticoagulant discontinuation, with $21 \%$ of patients developing the composite endpoint in the warfarin group vs. $24 \%$ in the placebo group (hazard ratio 0.75 ; $95 \%$ CI $0.47-1.18$ ) during the 42 -month study period. Consistently, similar results were observed in a parallel study (PADIS-DVT), which differed from PADIS$\mathrm{PE}$ in that only patients diagnosed with first unprovoked isolated DVT were enrolled. The primary results were presented at the ISTH congress in 2017.46) Following the first 6 months of "standard" anticoagulation, extending anticoagulation for an additional 18 months was not asso- ciated with a long-term reduction in the risk of recurrence or bleeding after discontinuation with the composite outcome occurring in $36.8 \%$ patients in the warfarin and in $31.5 \%$ in the placebo group (hazard ratio, $0.72 ; 95 \%$ CI $0.35-1.46) .{ }^{46)}$ Taken together, the PADIS studies underline the need for (i) selecting patients who could benefit most from extended, indefinite continuation of the anticoagulant treatment ${ }^{47-49)}$; (ii) determining which anticoagulant, and at which dosage, may provide the optimal balance between the prevention of recurrent VTE events and the risk of bleeding. ${ }^{50)}$

The concept of achieving effective secondary prevention with an acceptably low rate of major bleeding was explored in trials comparing the efficacy and safety of extended use of NOACs with either placebo or VKA. Consistently, the results of these studies demonstrated the effectiveness and safety of NOACs. ${ }^{51-53)}$ More recently, the EINSTEIN CHOICE trial investigated whether full- or lower-intensity anticoagulation therapy with rivaroxaban was effective and safe for patients who already completed 6 to 12 months of anticoagulation therapy after acute VTE. ${ }^{54)}$ In this study, 3,365 patients were randomized to receive either once-daily rivaroxaban (at doses of $20 \mathrm{mg}$ or $10 \mathrm{mg}$ ) or $100 \mathrm{mg}$ of aspirin. The primary efficacy endpoint (symptomatic recurrent VTE) occurred in 1.5\% receiving therapeutic-dose rivaroxaban $(20 \mathrm{mg})$, in $1.2 \%$ receiving rivaroxaban $10 \mathrm{mg}$, and in $4.4 \%$ receiving aspirin, indicating similar risk reduction with both rivaroxaban dosing (hazard ratio 0.34 [95\% CI $0.20-0.59$ ] and 0.26 [95\% CI 0.14-0.47], respectively). The rates of the primary safety endpoint did not differ among the groups $\left(0.5 \%, 0.4 \%\right.$, and $0.3 \%$, respectively). ${ }^{54)}$

\section{Cancer-associated pulmonary embolism and deep vein thrombosis}

The pathophysiological, epidemiological and clinical relevance of the association between VTE and cancer is well documented.55) The consensus that weight-adjusted subcutaneous low molecular weight heparin should be considered for the first 3-6 months instead of oral anticoagulants for patients with $\mathrm{PE}$ and cancer remained unchanged for many years. ${ }^{7,12,56)}$ After the publication of the phase III trials that led to the approval of NOAC, post hoc analyses of the patients with active cancer or history of cancer as well as a meta-analysis of the cancer patients included in all phase 3 NOAC trials on the treatment of VTE $^{56-58)}$ suggested a good efficacy and safety profile for these drugs compared to VKA. However, it is only recently that the results of two large trials comparing NOAC with low molecular weight heparin were presented, ${ }^{59)}$ or published. ${ }^{60)}$

In Select-d, ${ }^{59)} 406$ cancer patients were randomized to receive either dalteparin $(200 \mathrm{IU} / \mathrm{kg}$ daily, month 1 and 
$150 \mathrm{IU} / \mathrm{kg}$, months 2-6 after VTE diagnosis) or rivaroxaban $(15 \mathrm{mg}$ twice daily for 3 weeks then $20 \mathrm{mg}$ once daily, for 6 months in total) after the diagnosis of acute VTE. The outcomes included symptomatic or incidental PE and symptomatic lower extremity proximal deep vein thrombosis (DVT). After 6 months of treatment with either rivaroxaban or dalteparin, DVT patients who were positive for residual vein thrombosis by compression ultrasound and patients with PE at presentation, could be randomized to placebo or rivaroxaban for a further 6 months. The 6-month VTE recurrence rate was 11\% (95\% CI 7-17\%) for patients on dalteparin and 4\% (95\% CI 2-9\%) on rivaroxaban. Although the rate of major bleeding was not different between the treatment groups $(3 \%$ and $4 \%$, respectively), there were more clinically relevant non-major bleeding events in the rivaroxaban arm $(2 \%$ vs $13 \%$, respectively). Survival at 6 months was $70 \%$ on dalteparin and $74 \%$ on rivaroxaban. ${ }^{59}$

In the Hokusai-Cancer study, ${ }^{60)} 1,050$ cancer patients diagnosed with acute symptomatic or incidental VTE were randomly assigned to receive either low-molecularweight heparin for at least 5 days followed by oral edoxaban at a dose of $60 \mathrm{mg}$ once daily. The comparator arm consisted of subcutaneous dalteparin at a dose of $200 \mathrm{IU}$ per kilogram of body weight once daily for one month followed by dalteparin at a dose of $150 \mathrm{IU}$ per kilogram once daily. The duration of treatment was left at the discretion of the treating physicians and ranged between 6 and 12 months. The primary composite outcome included recurrent venous thromboembolism or major bleeding during the 12 months after randomization. It occurred in 67 patients $(12.8 \%)$ in the edoxaban group vs $71(13.5 \%)$ in the dalteparin group for a hazard ratio of 0.97 (95\% CI 0.70-1.36). The rate of recurrent VTE was lower in NOAC-treated patients $(-3.4 \%, 95 \%$ CI $-7.0-0.2)$; however, more bleeding events were observed $(+2.9 \%$ in the edoxaban arm, 95\% CI 0.1-5.6). Importantly, the larger reduction in recurrent events was observed for recurrent DVT $(3.6 \%$ in the edoxaban and $6.7 \%$ in the dalteparim arm; hazard ratio 0.56 ; $95 \%$ CI $0.32-0.97$ ) vs recurrent PE $(5.2 \%$ vs $5.3 \%$, respectively; hazard ratio $1.00 ; 95 \%$ CI $0.59-1.69)$. The mortality rates were similar in the two groups ( $39.5 \%$ vs $36.6 \%$, respectively). $\left.{ }^{60}\right)$

These recent data on the comparison between NOACs and low molecular weight heparins may help the physicians to determine the optimal anticoagulation strategy in this patient population. Both trials suggested that, in patients with active cancer and a diagnosis of acute VTE, the treatment with rivaroxaban or edoxaban is noninferior to standard treatment with low molecular weight heparin, if one accounts for the combined risk of recurrence and major bleeding. The key element for tailoring anticoagulant treatment in patients with active cancer and acute VTE will be represented by an individualized treatment based on the estimated risk of these two complications. The patient's preference for oral therapy in this context, on the one hand, and potential interactions with chemotherapeutic drugs, on the other hand, also represent important factors that must be taken into account.

\section{Specific patient groups and new possible indica- tions for anticoagulation}

Table 3 summarizes the major ongoing trials on the use of NOACs in specific patient populations of patients diagnosed with acute PE or VTE. Among those which are investigator initiated, a prospective multicenter management trial is focusing on the safety and efficacy of dabigatran in the treatment of patients with acute intermediate-risk PE defined by imaging (echocardiographic or CT) and laboratory (circulating levels of cardiac troponins and natriuretic peptides) parameters and their combinations. ${ }^{61)}$ At the low end of the PE severity spectrum, a prospective multicenter management trial has set out to determine whether early discharge and out-of-hospital treatment of patients with "low-risk" PE (on the basis of clinical criteria combined with the exclusion of right ventricular dysfunction and intracardiac thrombi) with rivaroxaban is feasible and safe; in addition, the trial will obtain health economic variables as the basis for description of resource utilization. ${ }^{62)}$ The results from both of the trials are expected to be available in 2019 .

\section{Conclusion}

Pulmonary embolism is a significant contributor to acute and chronic mortality and morbidity. Beyond pharmacological and, if necessary, mechanical circulatory support of the failing right ventricle, systemic thrombolysis remains the mainstay of treatment for hemodynamically unstable patients with "high-risk" PE. Catheter-directed, possibly ultrasound-facilitated low-dose local thrombolysis has emerged as a promising option for minimizing major bleeding risk while maintaining reperfusion efficacy. Non-vitamin K-dependent oral anticoagulants directly inhibiting factor Xa (rivaroxaban, apixaban, edoxaban) or thrombin (dabigatran), are evolving into the new standard of care in VTE treatment and secondary prophylaxis, since they can simplify initial, long-term, and extended/ indefinite anticoagulation after PE while reducing major bleeding risk.

\section{Acknowledgments}

The work of Stavros Konstantinides and Stefano Barco is supported by the German Federal Ministry of Education and Research (BMBF 01EO1003 and 01EO1503). 


\section{Disclosure Statement}

Stavros Konstantinides reports having received consultancy and lecture honoraria $(>1,000,000 \mathrm{JPY})$ from Bayer HealthCare; and institutional grants $(>1,000,000$ JPY) from Actelion, Bayer, Boehringer Ingelheim, DaiichiSankyo and Pfizer-Bristol-Myers Squibb. Stefano Barco has received congress and travel payments (>50,000 JPY) from Daiichi-Sankyo and Bayer HealthCare.

\section{Author Contributions}

Study conception: SK

Data collection: SK, SB

Analysis: SB

Investigation: $\mathrm{SB}, \mathrm{SK}$

Writing: SB, SK

Funding acquisition: SK, SB

Critical review and revision: all authors

Final approval of the article: all authors

Accountability for all aspects of the work: all authors

\section{References}

1) Becattini C, Agnelli G, Lankeit M, et al. Acute pulmonary embolism: mortality prediction by the 2014 European Society of Cardiology risk stratification model. Eur Respir J 2016; 48: 780-6.

2) Klok FA, van der Hulle T, den Exter PL, et al. The post-PE syndrome: a new concept for chronic complications of pulmonary embolism. Blood Rev 2014; 28: 221-6.

3) Lang IM, Pesavento R, Bonderman D, et al. Risk factors and basic mechanisms of chronic thromboembolic pulmonary hypertension: a current understanding. Eur Respir J 2013; 41: 462-8.

4) Barco S, Woersching AL, Spyropoulos AC, et al. European Union-28: an annualised cost-of-illness model for venous thromboembolism. Thromb Haemost 2016; 115: 800-8.

5) Mahan CE, Borrego ME, Woersching AL, et al. Venous thromboembolism: annualised United States models for total, hospital-acquired and preventable costs utilising longterm attack rates. Thromb Haemost 2012; 108: 291-302.

6) Mahan CE, Barco S, Spyropoulos AC. Cost-of-illness model for venous thromboembolism. Thromb Res 2016; 145: 1302.

7) Konstantinides SV, Torbicki A, Agnelli G, et al. 2014 ESC guidelines on the diagnosis and management of acute pulmonary embolism: the task force for the diagnosis and management of acute pulmonary embolism of the European Society of Cardiology (ESC) endorsed by the European Respiratory Society (ERS). Eur Heart J 2014; 35: 3033-73.

8) Laporte S, Mismetti P, Decousus H, et al. Clinical predictors for fatal pulmonary embolism in 15520 patients with venous thromboembolism: findings from the Registro Informatizado de la Enfermedad TromboEmbolica venosa (RIETE) registry. Circulation 2008; 117: 1711-6.

9) Harjola VP, Mebazaa A, Čelutkienė J, et al. Contemporary management of acute right ventricular failure: a statement from the heart failure association and the working group on pulmonary circulation and right ventricular function of the European Society of Cardiology. Eur J Heart Fail 2016; 18: 226-41.

10) Konstantinides S. Acute pulmonary embolism. Clinical practice. N Engl J Med 2008; 359: 2804-13.

11) Jaff MR, McMurtry MS, Archer SL, et al. Management of massive and submassive pulmonary embolism, iliofemoral deep vein thrombosis, and chronic thromboembolic pulmonary hypertension: a scientific statement from the American Heart Association. Circulation 2011; 123: 1788-830.

12) Kearon C, Akl EA, Ornelas J, et al. Antithrombotic therapy for VTE disease: CHEST guideline and expert panel report. Chest 2016; 149: 315-52.

13) Marti C, John G, Konstantinides S, et al. Systemic thrombolytic therapy for acute pulmonary embolism: a systematic review and meta-analysis. Eur Heart J 2015; 36: 605-14.

14) Meyer G, Vicaut E, Danays T, et al. Fibrinolysis for patients with intermediate-risk pulmonary embolism. N Engl J Med 2014; 370: 1402-11.

15) Wang C, Zhai Z, Yang Y, et al. Efficacy and safety of low dose recombinant tissue-type plasminogen activator for the treatment of acute pulmonary thromboembolism: a randomized, multicenter, controlled trial. Chest 2010; 137: 254-62.

16) Sharifi M, Bay C, Skrocki L, et al. Moderate pulmonary embolism treated with thrombolysis (from the "MOPETT" Trial). Am J Cardiol 2013; 111: 273-7.

17) Engelberger RP, Kucher N. Ultrasound-assisted thrombolysis for acute pulmonary embolism: a systematic review. Eur Heart J 2014; 35: 758-64.

18) Kucher N, Boekstegers P, Müller OJ, et al. Randomized, controlled trial of ultrasound-assisted catheter-directed thrombolysis for acute intermediate-risk pulmonary embolism. Circulation 2014; 129: 479-86.

19) Piazza G, Hohlfelder B, Jaff MR, et al. A prospective, singlearm, multicenter trial of ultrasound-facilitated, catheterdirected, low-dose fibrinolysis for acute massive and submassive pulmonary embolism: the SEATTLE II study. JACC Cardiovasc Interv 2015; 8: 1382-92.

20) Kuo WT, Banerjee A, Kim PS, et al. Pulmonary Embolism Response to Fragmentation, Embolectomy, and Catheter Thrombolysis (PERFECT): initial results from a prospective multicenter registry. Chest 2015; 148: 667-73.

21) Serhal M, Haddadin IS, Heresi GA, et al. Pulmonary embolism response teams. J Thromb Thrombolysis 2017; 44: 19-29.

22) Zhou Y, Li W, Herath C, et al. Off-hour admission and mortality risk for 28 specific diseases: a systematic review and meta-analysis of 251 cohorts. J Am Heart Assoc 2016; 5: e003102.

23) Nanchal R, Kumar G, Taneja A, et al. Pulmonary embolism: the weekend effect. Chest 2012; 142: 690-6.

24) Kabrhel C, Rosovsky R, Channick R, et al. A multidisciplinary pulmonary embolism response team: initial 30-month experience with a novel approach to delivery of care to patients with submassive and massive pulmonary embolism. Chest 2016; 150: 384-93.

25) Monteleone PP, Rosenfield K, Rosovsky RP. Multidisciplinary pulmonary embolism response teams and systems. 
Cardiovasc Diagn Ther 2016; 6: 662-7.

26) Barnes G, Giri J, Courtney DM, et al. Nuts and bolts of running a pulmonary embolism response team: results from an organizational survey of the National PERT ${ }^{\mathrm{TM}}$ Consortium members. Hosp Pract 2017; 45: 76-80.

27) Deadmon EK, Giordano NJ, Rosenfield K, et al. Comparison of emergency department patients to inpatients receiving a Pulmonary Embolism Response Team (PERT) activation. Acad Emerg Med 2017; 24: 814-21.

28) Stevinson BG, Hernandez-Nino J, Rose G, et al. Echocardiographic and functional cardiopulmonary problems 6 months after first-time pulmonary embolism in previously healthy patients. Eur Heart J 2007; 28: 2517-24.

29) Chung T, Emmett L, Mansberg R, et al. Natural history of right ventricular dysfunction after acute pulmonary embolism. J Am Soc Echocardiogr 2007; 20: 885-94.

30) Kline JA, Nordenholz KE, Courtney DM, et al. Treatment of submassive pulmonary embolism with tenecteplase or placebo: cardiopulmonary outcomes at 3 months: multicenter double-blind, placebo-controlled randomized trial. J Thromb Haemost 2014; 12: 459-68.

31) Konstantinides SV, Vicaut E, Danays T, et al. Impact of thrombolytic therapy on the long-term outcome of intermediate-risk pulmonary embolism. J Am Coll Cardiol 2017; 69: 1536-44.

32) Becattini C, Agnelli G. Treatment of venous thromboembolism with new anticoagulant agents. J Am Coll Cardiol 2016; 67: 1941-55.

33) Chan NC, Eikelboom JW, Weitz JI. Evolving treatments for arterial and venous thrombosis: role of the direct oral anticoagulants. Circ Res 2016; 118: 1409-24.

34) Nakamura M, Nishikawa M, Komuro I, et al. Apixaban for the treatment of Japanese subjects with acute venous thromboembolism (AMPLIFY-J Study). Circ J 2015; 79: 1230-6.

35) Yamada N, Hirayama A, Maeda H, et al. Oral rivaroxaban for Japanese patients with symptomatic venous thromboembolism - the J-EINSTEIN DVT and PE program. Thromb J 2015; 13: 2.

36) Nakamura M, Wang YQ, Wang C, et al. Efficacy and safety of edoxaban for treatment of venous thromboembolism: a subanalysis of East Asian patients in the Hokusai-VTE trial. J Thromb Haemost 2015; 13: 1606-14.

37) Lee YJ. Use of novel oral anticoagulants for the treatment of venous thromboembolism and its considerations in Asian patients. Ther Clin Risk Manag 2014; 10: 841-50.

38) Senoo K, Kondo Y, Miyazawa K, et al. Safety and efficacy of direct oral anticoagulants over warfarin in Japanese patients with acute venous thromboembolism: a meta-analysis. J Cardiol 2017; 69: 763-8.

39) Nakamura M, Yamada N, Ito M. Direct oral anticoagulants for the treatment of venous thromboembolism in Japan. J Atheroscler Thromb 2017; 24: 560-5.

40) Ageno W, Mantovani LG, Haas S, et al. Safety and effectiveness of oral rivaroxaban versus standard anticoagulation for the treatment of symptomatic deep-vein thrombosis (XALIA): an international, prospective, non-interventional study. Lancet Haematol 2016; 3: e12-21.

41) Klok FA, Barco S, Konstantinides SV. External validation of the VTE-BLEED score for predicting major bleeding in stable anticoagulated patients with venous thromboembo- lism. Thromb Haemost 2017; 117: 1164-70.

42) Heidbuchel H, Verhamme P, Alings $M$, et al. Updated European Heart Rhythm Association Practical Guide on the use of non-vitamin $\mathrm{K}$ antagonist anticoagulants in patients with non-valvular atrial fibrillation. Europace 2015; 17: 1467-507.

43) Connolly SJ, Milling TJ Jr, Eikelboom JW, et al. Andexanet alfa for acute major bleeding associated with factor $\mathrm{Xa}$ inhibitors. N Engl J Med 2016; 375: 1131-41.

44) Levy JH, Ageno W, Chan NC, et al. When and how to use antidotes for the reversal of direct oral anticoagulants: guidance from the SSC of the ISTH. J Thromb Haemost 2016; 14: 623-7.

45) Couturaud F, Sanchez O, Pernod G, et al. Six months vs extended oral anticoagulation after a first episode of pulmonary embolism: the PADIS-PE randomized clinical trial. JAMA 2015; 314: 31-40.

46) Couturaud F, Pernod G, Tromeur C, et al. Two years versus six months of oral anticoagulation after a first episode of unprovoked proximal deep vein thrombosis: the PADIS DVT multicenter, double-blind, randomized trial. ISTH Congress 2017; ASY 14.1.

47) Rodger MA, Le Gal G, Anderson DR, et al. Validating the HERDOO2 rule to guide treatment duration for women with unprovoked venous thrombosis: multinational prospective cohort management study. BMJ 2017; 356: j1065.

48) Tosetto A, Iorio A, Marcucci M, et al. Predicting disease recurrence in patients with previous unprovoked venous thromboembolism: a proposed prediction score (DASH). J Thromb Haemost 2012; 10: 1019-25.

49) Eichinger S, Heinze G, Jandeck LM, et al. Risk assessment of recurrence in patients with unprovoked deep vein thrombosis or pulmonary embolism: the Vienna prediction model. Circulation 2010; 121: 1630-6.

50) Konstantinides SV, Barco S, Lankeit M, et al. Management of pulmonary embolism: an update. J Am Coll Cardiol 2016; 67: 976-90.

51) Agnelli G, Buller HR, Cohen A, et al. Apixaban for extended treatment of venous thromboembolism. N Engl J Med 2013; 368: 699-708.

52) EINSTEIN investigators. Oral rivaroxaban for symptomatic venous thromboembolism. N Engl J Med 2010; 363: 2499510.

53) Schulman S, Kearon C, Kakkar AK, et al. Extended use of dabigatran, warfarin, or placebo in venous thromboembolism. N Engl J Med 2013; 368: 709-18.

54) Weitz JI, Lensing AWA, Prins MH, et al. Rivaroxaban or aspirin for extended treatment of venous thromboembolism. N Engl J Med 2017; 376: 1211-22.

55) Farge D, Debourdeau P, Beckers M, et al. International clinical practice guidelines for the treatment and prophylaxis of venous thromboembolism in patients with cancer. J Thromb Haemost 2013; 11: 56-70.

56) Vedovati MC, Germini F, Agnelli G, et al. Direct oral anticoagulants in patients with VTE and cancer. Chest 2015; 147 : 475-83.

57) Prins MH, Lensing AW, Brighton TA, et al. Oral rivaroxaban versus enoxaparin with vitamin $\mathrm{K}$ antagonist for the treatment of symptomatic venous thromboembolism in patients with cancer (EINSTEIN-DVT and EINSTEIN-PE): a pooled 
subgroup analysis of two randomised controlled trials. Lancet Haematol 2014; 1: e37-46.

58) Raskob GE, van Es N, Segers A, et al. Edoxaban for venous thromboembolism in patients with cancer: results from a non-inferiority subgroup analysis of the Hokusai-VTE randomised, double-blind, double-dummy trial. Lancet Haematol 2016; 3: e379-87.

59) Young AM, Marshall A, Thirlwall J, et al. Comparison of an oral Factor Xa inhibitor with low molecular weight heparin in patients with cancer with venous thromboembolism: results of a randomized trial (SELECT-D). J Clin Oncol 2018; 36: 2017-23.

60) Raskob GE, van Es N, Verhamme P, et al. Edoxaban for the treatment of cancer-associated venous thromboembolism. N Engl J Med 2018; 378: 615-24.
61) Klok FA, Ageno W, Barco S, et al. Dabigatran after short heparin anticoagulation for acute intermediate-risk pulmonary embolism: rationale and design of the single-arm PEITHO-2 study. Thromb Haemost 2017; 117: 2425-34.

62) Barco S, Lankeit M, Binder $H$, et al. Home treatment of patients with low-risk pulmonary embolism with the oral factor Xa inhibitor rivaroxaban. Rationale and design of the HoT-PE Trial. Thromb Haemost 2016; 116: 191-7.

63) Klok FA, Hösel V, Clemens A, et al. Prediction of bleeding events in patients with venous thromboembolism on stable anticoagulation treatment. Eur Respir J 2016; 48: 1369-76.

64) Schulman S, Kakkar AK, Goldhaber SZ, et al. Treatment of acute venous thromboembolism with dabigatran or warfarin and pooled analysis. Circulation 2014; 129: 764-72. 